\title{
Trans fatty acid content of takeaway food in Merseyside, UK
}

\author{
I. G. Davies, T. Blackham ${ }^{1}$, J. C. Abayomi ${ }^{1}$, C. Taylor ${ }^{2}$, M. Ashton ${ }^{2}$ and L. Stevenson ${ }^{3}$ \\ ${ }^{1}$ Nutrition and Health Research Group, Liverpool John Moores University, Liverpool, L17 6BD, UK, ${ }^{2}$ Knowsley Council, \\ Huyton, L36 9FB and ${ }^{3}$ Human Nutrition Research Centre, Newcastle University (Singapore), Nanyang Polytechnic, \\ 180 Ang Mo Kio Ave 8, Singapore 569830
}

Consumer food consumption has changed over the last few decades with food prepared outside the home increasing in popularity, including takeaway food from small independent establishments. Food prepared outside of the home tends to be energy dense, higher in fat, saturated fatty acids (SFA), sugar and salt ${ }^{(1,2)}$. In addition, high levels of trans fatty acids (TFA) have been reported from fast food chains and TFA are associated with increased risk of coronary heart disease ${ }^{(3)}$. There are no data on the TFA content of takeaway food from independent establishments in the UK. Therefore, the aim of the present study was to analyse the TFA content of popular takeaway foods from various meal categories of independent establishments in the Wirral and Knowsley regions of Merseyside, UK. Samples of takeaway meals $(n=266)$ were collected from small independent establishments and sent for analysis by an accredited public analyst laboratory. Total TFA content was analysed in $\mathrm{g} / 100 \mathrm{~g}$ and calculated $\mathrm{g} / \mathrm{meal}$. Meal categories were compared using the Kruskal-Wallis Test. Results revealed a high variability in the amount of TFA within meals and showed a statistically significant difference between meal categories ( $p=0.000$, Figure). Kebab meals were the highest in TFA with up to $5.2 \mathrm{~g}$ per meal. When compared to UK recommendations ( $\sim 5 \mathrm{~g} /$ day) Doner kebab and chips equalled this recommendation from just one meal.
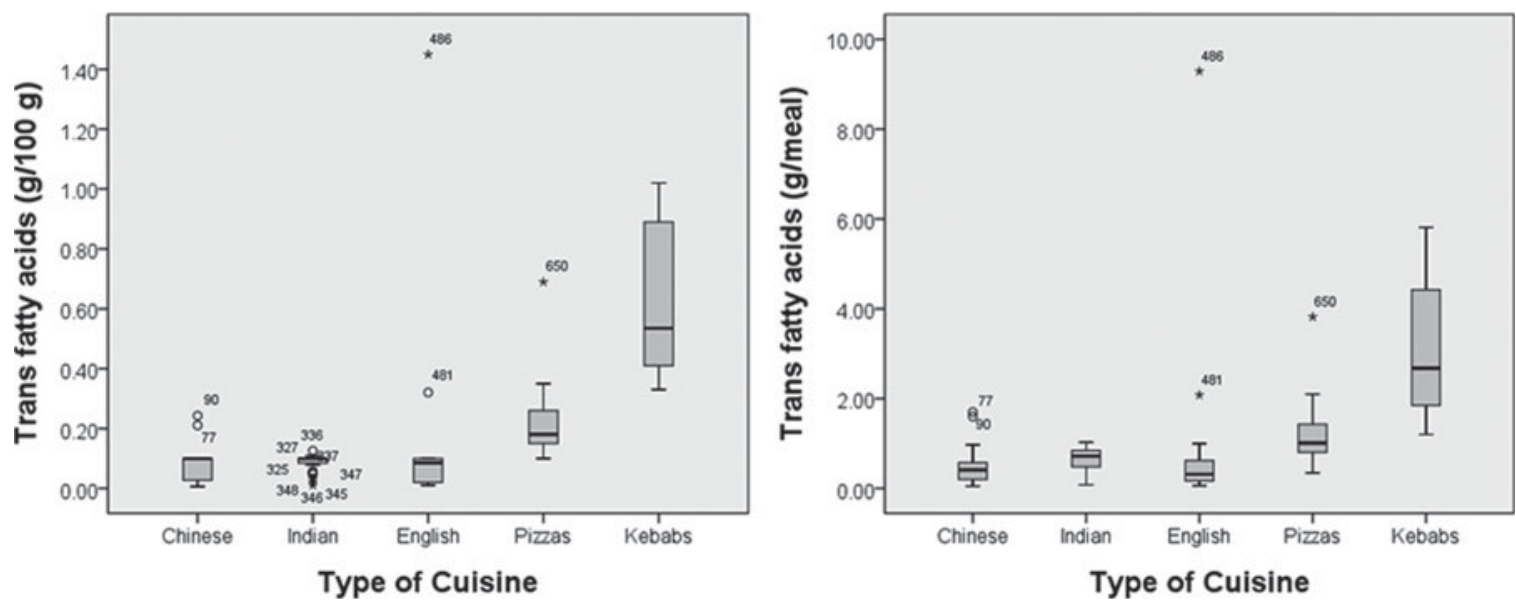

Fig. 1. Comparison of TFA content per $100 \mathrm{~g}$ and per meal by meal category.

While TFA have recently shown a reduction in the UK population to $0.7-0.9 \%$ of energy intake for all ages, food eaten out of the home has increased. The current study shows certain takeaway foods to be excessively high in TFA, and frequent consumption would increase the risk of coronary heart disease. We previously reported takeaway food to be high in salt ${ }^{(2)}$ and others have shown fast foods to be high in SFA and sugar ${ }^{(1)}$ and evidence suggest that frequent consumption of takeaway food increases the risk of obesity and insulin resistance ${ }^{(4)}$. The current study adds to the literature showing certain takeaway food is also high in TFA. Further evidence is warranted to establish the type of TFA in takeaway food and the frequency and amount of consumption.

1. Dunford E, Webster J, Barzi F et al. (2010) Appetite 55(3), 484-489.

2. Jaworowska A, Blackham T, Stevenson L et al. (2012) Appetite 59, 517-522.

3. Stender S, Dyerberg J, Astrup A (2006) N. Engl J. Med. 13;354(15), 1650-1652.

4. Smith KJ, Blizzard L, McNaughton SA (2012) Eur J Clin Nutr 66(5), 577-584. 